\title{
Prof. Dirk Durrer, godfather of Dutch cardiology A personal note *
}

On March 3, 1984 Professor Dirk Durrer died at an age of nearly 66 years in his home in Amsterdam. For those people who were close to him and have known him well, it is hardly possible to give a fair account of this man as a person and as a scientist. He was like a diamond sparkling from whatever angle you looked at him. It was impossible to be in a room with Durrer without literally feeling his vibrant presence. When you had left, his presence was still under your skin. I, at least, could never close the door of his house or his office and start to think of something else right away. You wondered about the unspoken meaning of his words and about what he had said which you might not have understood.

I met Durrer for the first time in 1957. He had recently been nominated as Professor of Cardiology and Clinical Physiology at the University of Amsterdam. At that time I was a fellow in internal medicine in Amsterdam. In my spare hours I was working with isolated, perfused rat hearts. I recorded their contractions and the unipolar left ventricular electrogram. That electrogram had a very peculiar shape with a $T$ wave that seemed part of the QRS complex. Nobody in those days could describe this form, let alone explain it.

I did not know Professor Durrer at that time, but a friend told me to go and see him and show him the record. He looked at it for 10 milliseconds and said: "Why don't you come and work with me and we will find out".

That remark changed my life completely, professionally and personally. It probably changed his life a little bit as well. I soon learned that Durrer wanted to build a set-up for isolated, revived and perfused human hearts. It took 7 years to finish it and in the meantime we worked and worked. The years I worked with him from 1958 till 1968 were the very best in my life. There was no day without learning something new. The walls of his laboratory were bulging outward all the lime, filled with visitors, laughter, enthusiasm and results. Durrer shaped modern electrocardiology in those days. I may mention the work on total excitation of the human heart, the studies on excitability of the myocardium, the calcium paradox, post-extrasystolic potentiation, experimental programmed electrical stimulation, epicardial and intramural excitation of acute and chronic myocardial infarctions in the dog and you name it. His ideas on re-entry tachycardias took shape in those days and he was happy to find a cardiac surgeon in Leiden who would help him with this concept in the Wolff-Parkinson-White syndrome.

* From the Department of Cardiology, University Hospital. Utrecht. The Netherlands. 
Durrer realized that any impact on mortality from myocardial infarction had to take place at the very beginning of the event. Durrer was, as it were. inside the heart. He could see and feel what was going on and had understood all kinds of phenomena before his bystanders had even noticed them. The speed of his mind has surprised me, almost till the day he died. As a matter of fact he surprised everybody. Many of his ideas were unexpected and full of brand-new logic and beauty. Durrers religion was his love for life and for everything that lived. He was just as enthusiastic about the counter-current principle and the permeability of the cell membrane of a Coli bacterium as he was about the monophasic action potential of a Purkinje fibre. He inspired his pupils, co-workers and friends. He added energy to the people close to him and brought them to a higher spiritual orbit. Even those cardiologists who did not train with him. but came to know him well, were inspired and changed by his thoughts and ideas.

Cardiology in Amsterdam, and to a large extent in The Netherlands, was and is Durrer's cardiology. Durrer is considered the godfather of present day Dutch cardiology. More than that, he is one of the founders of modern electrocardiology. His work and achievements are well known in the United States and the world over. His bibliography contains nearly 500 citations. In March 1983 he received the Distinguished Scientist Award of the American College of Cardiology in recognition of his great contributions to electrocardiology. Professor Durrer served with distinction on a number of national and international advisory councils and he was a member of several prestigious national and international scientific societies. He was a master teacher of the American College of Cardiology and was a member of the editorial boards of, among others. Circulation Research, the American Heart Journal, Chest and Clinical Cardiology. He was one of the advisors of the chief-editor of the European Journal of Cardiolog:. He was the president of the meeting of the European Society of Cardiology in Amsterdam in 1976. He was a scientific and political non-conformist for whom boundaries did not exist. He knew everybody and everybody knew him. He was a compulsive reader of the classical cardiological literature. He admired Claude Bernard and followed his footsteps by applying his principle of the "Autopsie physiologique". the revived isolated human heart being the ultimate example of this.

Probably his most visionary creation has been the Interuniversity Cardiology Institute which unites the departments of cardiology of all eight medical schools in The Netherlands. This combined effort allows us to use more efficiently the available talent in cardiovascular research in The Netherlands. The primary scientific goal of the Institute is the study of the causes of sudden cardiac death and of the ways of reducing mortality from coronary heart disease.

The presence of this Institute in The Netherlands will hopefully enable his inheritors to maintain the high international standard of Dutch cardiology in the years to come. It has been mainly Durrer's creative mind and efforts that have given The Netherlands the international prestige and recognition in cardiology it has today. We are grateful that the Imernational Journal of Cardiologv honors Durrer's timeless contributions to international cardiology.

But there is more. Durrer was a doctor. Not just a doctor with a stethoscope. but 
a doctor who really loved and helped his patients. When he sat down next to a patient's bed one could see that he or she already felt better. His way with children with a heart disease was just unbelievable. They trusted him after one second and at first sight. He was worshipped by his patients. It should be realized in this respect that nearly all of the splendid facilities he had in the "Wilhelmina Gasthuis" were gifts from patients. It was a unique occurrence that private funding had been allowed for the building of an institute on government owned terrain.

Finally, Durrer was a friend to his friends. He was always available to everybody. He loved the common man. but royalty and presidents of states were among his patients. He was, however. human as well; he certainly was not a saint. He made mistakes, errors of judgement and sometimes. if they did not live up to his expectations, he estranged himself from his friends. But all in all he was the most inspired teacher, the most gifted scientist and warmest human being I have ever known. It has been my privilege to have lived in the light, the warmth and the shade of this man.

('niversity Hospital

P.O. Box 16250

$3500 \mathrm{CG}$ Litrecht

The Netherlands

Frits L. Meijler 